\title{
HyphaNet: um algoritmo de roteamento bioinspirado em colônia de fungos para redes móveis ad hoc
}

\author{
Clovis Ronaldo da Costa Bento e Emilio Carlos Gomes Wille
}

\begin{abstract}
Resumo-Diversos protocolos de redes de comunicação são inspirados na natureza, por exemplo, em insetos sociais (formigas, abelhas, vaga-lumes, entre outros). Muitas espécies de fungos formam redes de hifas capazes de auto-organização, resiliência e eficiência na construção de redes de transporte de nutrientes. Isso inspira comparar o fenótipo fúngico a uma rede de comunicação. Nessa perspectiva, este artigo propõe um protocolo de roteamento para MANETs baseado no comportamento de fungos chamado de HyphaNet. O HyphaNet é do tipo reativo e multipath. Simulações no NS-2.35 mostram bom desempenho comparado ao AODV clássico e ao SARA baseado em formigas.
\end{abstract}

Palavras-Chave-MANETs, Rede de hifas, Roteamento bioinspirado, HyphaNet.

Abstract-Several communication network protocols are inspired by nature, for example, in social insects (ants, bees, fireflies, among others). Many species of fungi form networks of hyphae capable of self-organization, resilience and efficiency in building nutrient transport networks. This inspires comparing the fungal phenotype to a communication network. In this perspective, this article proposes a routing protocol for MANETs based on the behavior of fungi called HyphaNet. HyphaNet is reactive and multipath. NS-2.35 simulations show good performance compared to classic AODV and ant-based SARA.

Keywords-MANETs, Hyphae network, Bio-inspired routing, HyphaNet.

\section{INTRODUÇÃO}

As redes móveis ad hoc, conhecidas pela sigla MANETs (do inglês Mobile Ad Hoc Networks), ocupam espaço importante entre as tecnologias de comunicação sem fio atuais e tem importante papel e contribuição com o advento da Internet das Coisas (IoT). No cenário atual é crescente o interesse pelas redes móveis e as novas aplicações multimídia que permitem a qualquer pessoa viver e trabalhar de forma onipresente. Os maiores desafios das MANETs estão relacionados às questões de desempenho, devido à mobilidade e limitação dos recursos dos nós (processamento, buffer e consumo de energia). Assim, diversas propostas foram apresentadas nas últimas duas décadas para o avanço das MANETs, envolvendo não apenas novos protocolos mas também hardwares específicos para comunicação sem fio, como WI-FI, ZigBee, Bluetooth, LoRa, entre outros [1].

Assim como diversos sistemas foram inspirados no comportamento de insetos sociais (formigas, abelhas, entre

Clovis Ronaldo da Costa Bento, Departamento de Elétrica, Universidade Tecnológica Federal do Paraná, Cornélio Procópio-PR, e-mail: clovisbento@utfpr.edu.br; Emilio Carlos Gomes Wille, Programa de PósGraduação em Engenharia Elétrica e Informática Industrial, Universidade Tecnológica Federal do Paraná, Curitiba-PR, e-mail: ewille@utfpr.edu.br. outros), as colônias de fungos também demonstram potencial de bioinspiração por exibirem comportamento e capacidade para auto-organização de redes naturais adaptativas, robustas, resilientes e eficientes no transporte de nutrientes. $\mathrm{Na}$ dinâmica de crescimento de uma colônia de fungos, suas ramificações se expandem pelo solo com o objetivo de construir os melhores caminhos para transporte de nutrientes e garantir a sobrevivência o organismo. Estas características sugerem que um sistema que faz uso do conceito de fungos para o desenvolvimento de protocolos de roteamento pode apresentar um bom desempenho quando comparado aos sistemas convencionais. É importante salientar que, a ideia de buscar inspiração em redes de fungos é encontrada na literatura apenas para redes cabeadas, sem referências às redes móveis.

Este trabalho é uma extensão de um estudo recente [2] que propõe um protocolo de roteamento para MANETs desenvolvido a partir da observação de colônias de fungos, chamado HyphaNet. O HyphaNet provou ser ideal para redes com centenas de nós e cenário de tráfego baixo ou moderado. Esta extensão abrange, além da própria apresentação do protocolo, uma comparação entre as características funcionais do HyphaNet e aquelas de um algoritmo baseado em colônia de formigas, e principalmente resultados de novas simulações. Além disso, de modo a tornar este trabalho o mais auto-suficiente possível, também são apresentados conceitos referentes a roteamento para MANETs e colônias de fungos.

Este artigo está organizado da seguinte forma: A Seção 2 apresenta uma revisão sobre os principais conceitos relacionados a roteamento para MANETs. A Seção 3 fornece uma descrição básica das colônias de fungos e os processos biológicos chaves para a concepção do HyphaNet. A Seção 4 descreve o algoritmo HyphaNet, compreendendo os mecanismos de descoberta, manutenção e reparo de rotas. A Seção 5 mostra os resultados das simulações do HyphaNet em comparação com o AODV e o SARA. Finalmente, a Seção 6 apresenta as conclusões e sugestões para trabalhos futuros.

\section{REDES MÓVEIS ad hoc}

As MANETs consistem em conjuntos de dispositivos móveis de comunicação sem fio, que operam de forma descentralizada, usando roteamento com múltiplos saltos, onde os nós funcionam tanto como terminais ou roteadores de retransmissão sem qualquer infraestrutura fixa. Por ser uma rede móvel, sua topologia é dinâmica e possui capacidade de auto-organização para manter os processos de comunicação [3]. 
Na prática, há variantes de MANETs conforme aplicação:

1) WMNs (Wireless Mesh Networks). Rede heterogênea, com nós roteadores (conexão com outras redes) ou clientes, a mobilidade é reduzida ou inexistente [4];

2) DTNs (Delay Tolerant Networks). São redes oportunistas, tolerantes a atrasos/desconexões [5];

3) VANETs (Vehicular Ad Hoc Networks). São redes veiculares, o grau de mobilidade é elevado [6], [7];

4) WSN (Wireless Sensor Networks). Redes para detecção de eventos de interesse, a energia é um recurso escasso, baixa mobilidade [8];

5) FANETs (Flying Ad Hoc Networks). São redes compostas por veículos aéreos não tripulados, grande mobilidade e conectividade remota [9];

6) RWSN (Robotic Wireless Sensor Networks). Conjunto de robôs com capacidade de comunicação e cooperação [10].

\section{A. Roteamento Reativo, Proativo e Híbrido}

Os protocolos de roteamento reativo, ou roteamento sob demanda (on-demand), precisam realizar a descoberta de rotas sempre que iniciarem uma nova transmissão de dados, exceto se já houver rota disponível para o destino. Portanto, a sobrecarga é menor, tornando-os geralmente mais escaláveis, mas podem apresentar latências mais altas em função dos constantes processos de busca de rotas. Há três processos básicos no funcionamento das MANETs com roteamento reativo: descoberta, manutenção e recuperação de rotas. O AODV [11] e DSR [12], dentre outros, são exemplos clássicos de protocolos reativos.

$\mathrm{Na}$ abordagem proativa (table-driven), os protocolos trocam informações de topologia periodicamente, produzindo e mantendo rotas de forma sistemática, mesmo na ausência de tráfego. A desvantagem dessa abordagem é a sobrecarga para manter as tabelas de roteamento, especialmente se a topologia for altamente variável. Os protocolos DSDV [13] e OLSR [14] são bem conhecidos neste tipo de estratégia.

Os protocolos de roteamento híbrido têm características reativas e proativas. Os HWMP [15] e ZPR [16] são dois exemplos de protocolos híbridos.

\section{B. Roteamento Bioinspirado}

Protocolos de roteamento bioinspirado são aqueles baseados na natureza, por exemplo, na inteligência de enxames. Como exemplos tem-se as arquiteturas ACO (Ant Colony Optimization) [17] inspirada no estudo das colônias de formigas, na qual o comportamento das formigas otimiza o processo de busca por alimentos, sinalizando o caminho com feromônio, indicando direções e distâncias mais curtas, e ABC (Artificial Bee Colony) inspirada em abelhas. Esses processos são conhecidos como estigmergia [18]. O SARA [19] e o Bee-MANET [20] são exemplos de protocolos baseados em formigas e em abelhas, respectivamente.

\section{COlÔNIAS DE Fungos}

De acordo com a microbiologia, os fungos são organismos eucarióticos, unicelulares ou multicelulares, com estruturas

microscópicas ou macroscópicas, aeróbicas ou anaeróbias heterotróficas ou facultativas [21]. A Fig. 1 mostra exemplos comuns de fungos.

(a)

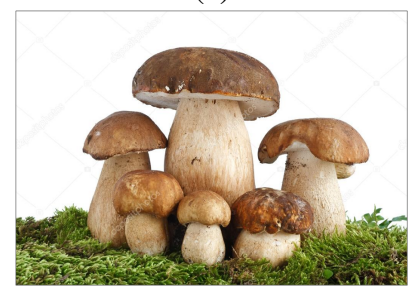

Fig. 1: Exemplos comuns de fungos: (a) Boletus edulis; (b) Pinicillium, fungo microscópico e filamentoso. Fonte: [22]

\section{A. Crescimento de fungos miceliais}

Alguns fungos existem na forma de leveduras e outros são do tipo filamentoso e multicelular. Os filamentos (ou hifas) são estruturas físicas, tubulares, do crescimento de fungos que formam a estrutura chamada micélio e começam com a germinação de esporos. As hifas se expandem e se ramificam, formando redes de absorção, reciclagem e transporte de nutrientes (ou biomassas) para o micélio [23].

Um fluxo de nutrientes é gerado pelo processo de absorção da fonte em direção ao destino, neste caso o destino é representado pelas extremidades dos hifas. A distribuição da biomassa pode ocorrer por difusão local ou translocação entre pontos distantes do micélio. As hifas que formam as rotas do fluxo de nutrientes recebem reforço na estrutura, enquanto que hifas ociosas são recicladas e desaparecem. Isso forma a ideia central da inspiração de fungos para redes de comunicação.

O fluxo de nutrientes é uma combinação de dois tipos de biomassa: biomassa imobilizada e biomassa móvel [24], conforme descrito abaixo:

1) Biomassa Imóvel - material usado para construir o micélio e a rede de hifas de transporte de biomassa móvel. Essa biomassa pode ser absorvida ou reciclada ao longo do tempo.

2) Biomassa móvel - material que flui através das hifas para as extremidades do micélio. Essa biomassa é reciclada para biomassa imóvel para gerar estruturas miceliais.

\section{B. Algoritmo FUNNet}

Um modelo matemático para o entendimento da dinâmica espaço-temporal do fenótipo fúngico, que incorpora os processos de reciclagem e transporte de biomassa foi descrito em [24]. Este modelo deu origem ao algoritmo FUNNet [25], que é uma proposta inspirada em redes de fungos para redes de comunicação com fio. A tabela I mostra uma analogia entre redes de fungos e redes de comunicação, proposta no FUNNet.

O FUNNet introduz um novo conceito de roteamento, no qual não há tabelas de roteamento e os nós não precisam ter informações sobre toda a rede, mas apenas para saber quem são seus vizinhos imediatos conectados por hifas. O processo de seleção de rota da FUNNet é baseado na atração por rotas com maior concentração de biomassa imóvel, indicando os 
locais com maior capacidade de transporte. Até o presente momento, o FUNNet é o único modelo de comunicação bioinspirado por fungos na literatura.

TABELA I: Rede de fungo vs. Rede de comunicação.

\begin{tabular}{ll}
\hline \multicolumn{1}{c}{ Rede de fungo } & \multicolumn{1}{c}{ Rede de comunicação } \\
\hline Hifa & Conexões entre nós \\
\hline Ponta das hifas & Nós da rede \\
\hline Micélio & Rede total ou tabela de rotas \\
\hline Biomassa móvel & Tráfego de dados \\
\hline $\begin{array}{l}\text { Mecanismo de transporte } \\
\text { de biomassa móvel }\end{array}$ & Regras de roteamento \\
\hline Biomassa imóvel & Capacidade ou atratividade \\
\hline Reciclagem de biomassa & $\begin{array}{l}\text { Interação entre tráfego de dados } \\
\text { e atração de fluxo }\end{array}$ \\
\hline Consumo de biomassa & $\begin{array}{l}\text { Redução da atração de tráfego } \\
\text { de dados ao longo do tempo }\end{array}$ \\
\hline Absorção de nutrientes & $\begin{array}{l}\text { Geração de pacote de dados para } \\
\text { enviar }\end{array}$ \\
\hline Morte da hifa & Desconexão do enlace \\
\hline
\end{tabular}

\section{Algoritmo Hyphanet}

O HyphaNet é um algoritmo de roteamento para MANETs inspirado no comportamento de colônias de fungos, do tipo sob demanda, multipath e opera sobre a arquitetura TCP/IP. De forma diferente dos protocolos tradicionais, a métrica de roteamento do HyphaNet baseia-se no conceito de "atratividade de nó". No micélio fúngico, o conceito de atratividade é usado para selecionar a melhor rota para o transporte de nutrientes através das redes de hifas. A atratividade varia conforme as hifas são utilizadas e acumulam biomassa imóvel. Da mesma forma, no HyphaNet as rotas são construídas e mantidas de acordo com o tráfego de dados, e o roteamento é baseado na conversão do fluxo de dados em biomassa imóvel artificial que representa atratividade para seleção de rotas. No processo de descoberta de rotas, o HyphaNet adota o método para redução da difusão chamado Controlled Neighbor Broadcast [26].

O modelo de atualização de roteamento do HyphaNet é mostrado nas Eqs. (1a) a (1f). A atualização é executada sempre que o pacote de dados é entregue com êxito no destino, com auxílio de uma mensagem de confirmação. Ao transmitir um pacote de dados, a origem também gera uma massa móvel $E$ artificial que será distribuída a todos os nós ao longo do caminho. Seja $B_{j}$ o tamanho do buffer da interface de rede (MAC) e $L_{j}$ a ocupação deste buffer, associado ao nó $j$, então, $A B S_{j}=\left(1-L_{j} / B_{j}\right)$ é o espaço disponível no buffer. A equação (1a) fornece a qualidade da rota, em função da distância $R$ (em saltos) e do espaço disponível no buffer, onde $j$ corresponde aos nós presentes nesta rota. Assim, cada nó $k$ (pertencente à rota) recebe uma fração $E \Lambda$ para acumular em sua massa móvel $\left(M_{k}\right)$, de acordo com a Eq. (1b).

$$
\begin{aligned}
\Lambda & =R^{-2} \sum_{j} A B S_{j}, \\
M_{k} & =M_{k}+E \Lambda, \\
\lambda & =\alpha M_{k}, \\
M_{k} & =M_{k}-\lambda, \quad \text { se } M_{k}>\lambda, \\
I_{k} & =I_{k}+\lambda, \\
I_{k} & =\beta I_{k} .
\end{aligned}
$$

Na Eq. (1c), $\lambda$ representa a quantidade de biomassa móvel $(M)$ convertida em imóvel $(I)$ e $\alpha$ é o fator de conversão. As Eqs. (1d) e (1e) efetivam a conversão. A Eq. (1f) corresponde ao consumo da biomassa imóvel onde $\beta$ é o fator de consumo. A convergência do algoritmo é assegurada se os valores $\alpha$ e $\beta$ são menores que a unidade. Assim, de acordo com o tráfego de dados, o sistema converte a biomassa móvel em imóvel, semelhante a fungos, resultando na otimização de rotas mais curtas e menos sobrecarregadas ao longo do tempo.

\section{A. Seleção de rotas}

O mecanismo de seleção de rotas utiliza informações de atratividade atualizadas nas tabelas de roteamento. Nesse modelo, a atratividade $G_{j}$ é uma informação local, obtida a partir dos elementos presentes nos nós $j$, na vizinhança do nó $i$. A Eq. (2) favorece as melhores rotas fornecendo a atratividade de um nó $j$, em que $I_{j}$ é a biomassa imóvel e $\mu$ e $\Omega$ são parâmetros do HyphaNet para ajuste de sensibilidade à biomassa ou à ocupação dos buffers.

$$
G_{j}=\left(I_{j}\right)^{\mu} \cdot\left(A B S_{j}\right)^{\Omega} .
$$

Assim, sempre que um pacote deve ser retransmitido por um nó roteador $i$ em direção ao destino $d$, este nó faz uma escolha aleatória com probabilidade dada pela Eq. (3), onde o nó $n$ corresponde ao próximo salto e $N_{i}^{d}$ é a vizinhança do nó $i$ com rota para o destino $d$.

$$
P_{i, n}^{d}=\frac{G_{n}}{\sum_{j \in N_{i}^{d}} G_{j}}, \quad \forall n \in N_{i}^{d} .
$$

\section{B. Comparação entre ACO e HyphaNet.}

Por ser um algoritmo bioinspirado, algumas das características funcionais do HyphaNet podem ser comparadas àquelas do algoritmo $\mathrm{ACO}$, pois têm funções comuns nas redes de comunicação. Os principais pontos envolvem as informações de rotas, a estrutura da tabela de roteamento e a heurística de seleção de rotas. A Tabela II mostra um resumo comparativo conceitual entre ACO e HyphaNet.

\section{SimulaÇÃo E ANÁlise}

As simulações do HyphaNet foram realizadas com o simulador NS-2.35. A tecnologia de redes utilizada no enlace e meio físico é o IEEE 802.11b (DCF) ajustado para taxa de 
transmissão de $11 \mathrm{Mbps}$, taxa básica de controle de quadros de $2 \mathrm{Mbps}$ e raio de transmissão de 250 metros. O cenário consiste em uma rede com 10 fontes de tráfego CBR/UDP, presentes em uma área de $1000 \times 1000 \mathrm{~m}^{2}$, transmitindo com pacotes de 512 bytes e taxa de envio de quatro pacotes/s [27].

$\mathrm{O}$ modelo de mobilidade considerado é o RWP (Random WayPoint $)$ com velocidades no intervalo $\left[V_{\min }=1, V_{\max }=\right.$ $20] \mathrm{m} / \mathrm{s}$ e tempos de pausa de $0,15,30,60,120 \mathrm{e}$ $240 \mathrm{~s}$. De acordo com [28] o RWP é um dos modelos de mobilidade mais populares para avaliar protocolos de roteamento em redes ad hoc móveis. Para cada pausa foram executadas 120 simulações da rede (rodadas), cada uma com $180 \mathrm{~s}$ de duração. Os modelos de mobilidade foram gerados distintamente para cada rodada. Os pares origemdestino são escolhidos aleatoriamente, e as fontes iniciam suas transmissões, também de forma aleatória, nos primeiros 35 $\mathrm{s}$ de simulação e permanecem transmitindo até o final. Os resultados finais são apresentados por seus valores médios e intervalo de confiança de $95 \%$. Os valores para os parâmetros HyphaNet que melhor resultado produziram (conforme testes preliminares) estão presentes na Tabela III.

TABELA II: Tabela comparativa.

\begin{tabular}{|c|c|}
\hline ACO & HyphaNet \\
\hline $\begin{array}{l}\text { Roteamento baseado em } \\
\text { informações de feromônio } \\
\text { nas tabelas de roteamento }\end{array}$ & $\begin{array}{l}\text { Roteamento baseado em } \\
\text { informações de atratividade } \\
\text { dos nós, proporcional à } \\
\text { biomassa imóvel }\end{array}$ \\
\hline $\begin{array}{l}\text { As características do enlace } \\
\text { predominam na definição do } \\
\text { caminho }\end{array}$ & $\begin{array}{l}\text { Caminho é predominantemente } \\
\text { definido pelas atratividade dos } \\
\text { nós }\end{array}$ \\
\hline $\begin{array}{l}\text { Rotas com maior concentração } \\
\text { de feromônio são mais } \\
\text { confiáveis e têm preferência }\end{array}$ & $\begin{array}{l}\text { Rotas com maior concentração } \\
\text { de massa imóvel são mais } \\
\text { atrativas e têm preferência }\end{array}$ \\
\hline $\begin{array}{l}\text { Rotas com maior capacidade de } \\
\text { tráfego atraem maior número } \\
\text { de formigas e, portanto, mais } \\
\text { feromônio }\end{array}$ & $\begin{array}{l}\text { Rotas com maior capacidade } \\
\text { de tráfego atraem mais fluxo } \\
\text { de massa móvel e, portanto, } \\
\text { mais geração de massa imóvel }\end{array}$ \\
\hline $\begin{array}{l}\text { Evaporação. O feromônio } \\
\text { evapora e desaparece nas rotas } \\
\text { ociosas, por não haver formigas } \\
\text { depositando feromônio }\end{array}$ & $\begin{array}{l}\text { Degradação. Em rotas ociosas } \\
\text { não há conversão de massa } \\
\text { móvel em imóvel e a massa } \\
\text { imóvel é absorvida até } \\
\text { desaparecer }\end{array}$ \\
\hline $\begin{array}{l}\text { Convergência natural para a } \\
\text { rota ótima pela distribuição de } \\
\text { feromônio acarretar maior } \\
\text { concentração em curtas } \\
\text { distâncias }\end{array}$ & $\begin{array}{l}\text { Convergência natural para a } \\
\text { rota ótima pela distribuição de } \\
\text { massa móvel ser fracionada } \\
\text { em cada um dos saltos na rota }\end{array}$ \\
\hline $\begin{array}{l}\text { A heurística de seleção de } \\
\text { rotas utiliza informações } \\
\text { de feromônios da tabela de } \\
\text { roteamento do nó local }\end{array}$ & $\begin{array}{l}\text { A heurística utiliza } \\
\text { informações de atratividade } \\
\text { calculada com valores de } I \text { e } \\
A B S \text { dos nós vizinhos }\end{array}$ \\
\hline $\begin{array}{l}\text { Informações de feromônios } \\
\text { de uma determinada rota não } \\
\text { influenciam rotas adjacentes }\end{array}$ & $\begin{array}{l}\text { A atratividade dos nós é } \\
\text { compartilhada entre vizinhos } \\
\text { e pode influenciar rotas } \\
\text { adjacentes }\end{array}$ \\
\hline
\end{tabular}

Dois protocolos de roteamento foram selecionados para fins de comparação: AODV e SARA. O AODV (Ad hoc
On-demand Distance Vector Routing) é descrito como um protocolo de roteamento dinâmico que determina rotas unicast para destinos dentro da rede com rápida convergência quando a topologia da rede é alterada. O SARA (Simple Ant Routing Algorithm) é um algoritmo reativo que armazena as informações de roteamento em tabelas de feromônios. Este protocolo, de elevado desempenho, utiliza agentes-formiga na descoberta de rotas e o tráfego de dados para a atualização dos feromônios, reduzindo a sobrecarga. O CNB é usado para redução da difusão. Ambos têm implementação no simulador NS-2. Os detalhes de configuração do protocolo SARA vêm de [19].

TABELA III: Parâmetros de simulação do HyphaNet.

\begin{tabular}{ll}
\hline \multicolumn{1}{c}{ Parâmetro } & \multicolumn{1}{c}{ Valor } \\
\hline Intervalo entre mensagens de Hello & $I_{H E L L O}=3 \mathrm{~s}$ \\
Fator de conversão de massa móvel & $\alpha=0,1$ \\
em imóvel & $\beta=0,95$ \\
Fator de consumo de massa imóvel & $\mu=2,0$ \\
Sensibilidade para biomassa imóvel & $\Omega=1,0$ \\
Sensibilidade para ocupação de buffers & $\Omega=1$ \\
\hline
\end{tabular}

Os resultados para as métricas atraso, taxa de entrega de pacotes e overhead são mostrados nas Figs. 2, 3 e 4. Notase que o HyphaNet apresenta excelentes resultados para um algoritmo bioinspirado, sendo ligeiramente inferior ao AODV somente no quesito overhead devido ao número de mensagens de confirmação que é proporcional ao tráfego de dados. Além disso, apresenta valores de overhead sensivelmente melhores que o SARA, com desempenho equivalente em atraso e taxa de entrega.

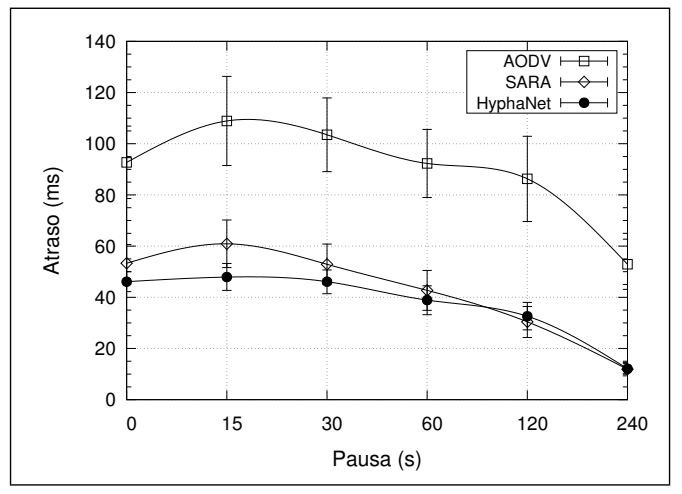

Fig. 2: Atraso de pacotes.

\section{CONCLUSÃO}

A ideia de se utilizar fungos como inspiração veio da convicção de que os fungos têm grande capacidade de adaptação e aptidão para sobrevivência em ambientes com escassez de recursos, e com uma atenta observação seria possível levar essas características para a área de redes MANETs. Assim, este trabalho considerou o mecanismo associado aos fungos filamentosos como metáfora para construir um algoritmo de roteamento funcional para redes de comunicação sem fio, o HyphaNet. 


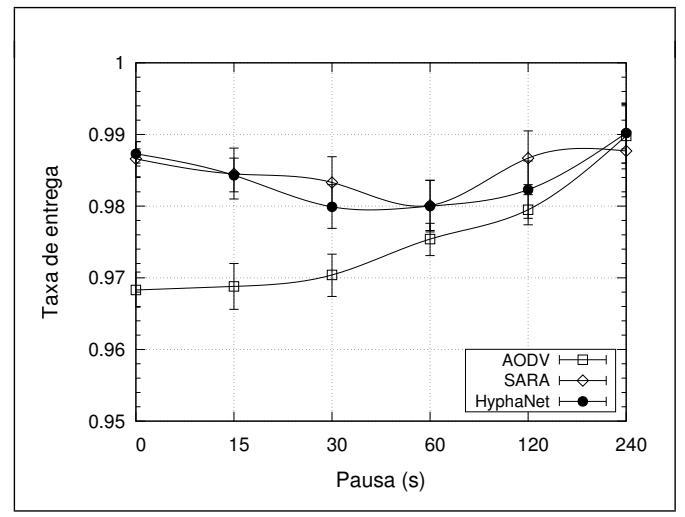

Fig. 3: Taxa de entrega de pacotes.

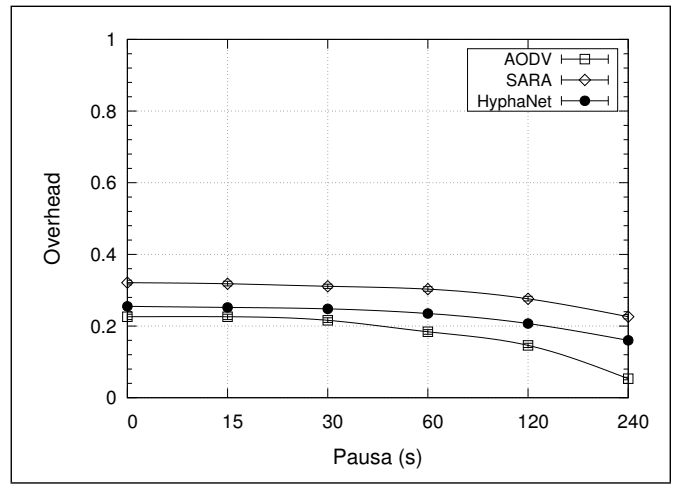

Fig. 4: Overhead.

Por ser um algoritmo bioinspirado, algumas das características funcionais do HyphaNet podem ser comparadas àquelas do algoritmo ACO. A principal semelhança entre HyphaNet e ACO é o processo de roteamento, envolvendo as informações de rotas, a estrutura da tabela de roteamento e a heurística de seleção de rotas. Entretanto, a principal diferença é o conceito de atratividade, dependente do nível de biomassa imóvel nos nós e da qualidade da rota, e cujo valor é compartilhado para toda a rede. No HyphaNet, o critério de seleção de rotas baseado na atratividade é função de dois fatores, um específico da abordagem por fungos (biomassa imóvel), e um que pode ser escolhido livremente pelo projetista. No presente trabalho foi escolhido o "espaço disponível em buffer", representado pela variável ABS, entretanto, outros "indicadores de qualidade" podem também ser considerados, por exemplo, nível de bateria, qualidade do sinal de rádio, entre outros. A escolha mais adequada dos parâmetros $\mu$ e $\Omega$ é tema de trabalho futuro.

Nas simulações, o HyphaNet mostrou que pode fornecer um bom desempenho em diversas métricas, sendo portanto promissor para futuras pesquisas. Como análise final, o HyphaNet pode ser recomendado para redes com centenas de nós, e aplicações sobre protocolos de transporte UDP e TCP em cenários de tráfego baixo ou moderado.

\section{REFERÊNCIAS}

[1] LoRaWAN, "LoRaWAN. What is it? A technical overview of LoRa and LoRaWAN," LoRa Alliance, Tech. Rep., 2015.
[2] C. R. da Costa Bento e E. C. G. Wille, "Bio-inspired routing algorithm for manets based on fungi networks," Ad Hoc Networks, vol. 107, 2020.

[3] N. Srivastava e P. Raghav, "A review on swarm intelligence based routing algorithms in mobile adhoc network," in 2017 8th International Conference on Computing, Communication and Networking Technologies (ICCCNT). IEEE, jul 2017.

[4] Karthika K.C, "Wireless mesh network: A survey," in 2016 International Conference on Wireless Communications, Signal Processing and Networking (WiSPNET). IEEE, mar 2016.

[5] Y. Mao, C. Zhou, Y. Ling, e J. Lloret, "An optimized probabilistic delay tolerant network (DTN) routing protocol based on scheduling mechanism for internet of things (IoT)," Sensors, vol. 19, no. 2, 2019.

[6] J. Alves Junior e E. C. G. Wille, "P-AOMDV: An improved routing protocol for $\mathrm{V} 2 \mathrm{~V}$ communication based on public transport backbones," Transactions on Emerging Telecommunications Technologies, 2016.

[7] B. V. Coutinho, E. C. G. Wille, e H. I. Del Monego, "Performance of routing protocols for VANETs: a realistic analysis format," in IMCOM'15, 2015.

[8] J. Wang, Y. Gao, W. Liu, A. K. Sangaiah, e H.-J. Kim, "An intelligent data gathering schema with data fusion supported for mobile sink in wireless sensor networks," International Journal of Distributed Sensor Networks, vol. 15, no. 3, p. 155014771983958, mar 2019.

[9] A. Guillen-Perez, R. Sanchez-Iborra, M.-D. Cano, J. C. SanchezAarnoutse, e J. Garcia-Haro, "WiFi networks on drones," in 2016 ITU Kaleidoscope: ICTs for a Sustainable World (ITU WT), 2016.

[10] P. Ghosh, A. Gasparri, J. Jin, e B. Krishnamachari, Robotic Wireless Sensor Networks. Cham: Springer International Publishing, 2019, pp. 545-595.

[11] C. Perkins, E. Belding-Royer, e S. Das, RFC 3561: Ad hoc On-Demand Distance Vector $(A O D V)$ Routing, T. I. Society, Ed. IETF. Network Working Group. Request for Comments: 3561, Jul. 2003.

[12] D. B. Johnson, D. A. Maltz, e Y.-C. Hu, The Dynamic Source Routing Protocol for Mobile Ad Hoc Networks (DSR). IETF Internet Draft, 2004.

[13] C. E. Perkins e P. Bhagwat, "Highly dynamic Destination-Sequenced Distance-Vector routing (DSDV) for mobile computers," in Proceedings of the conference on Communications architectures, protocols and applications - SIGCOMM 94. ACM Press, 1994.

[14] T. Clausen e P. Jacquet, Optimized Link State Routing Protocol (OLSR). The Internet Society, 2003, no. RFC 3626.

[15] G. Hiertz, D. Denteneer, S. Max, R. Taori, J. Cardona, L. Berlemann, e B. Walke, "IEEE 802.11s: The WLAN Mesh Standard," IEEE Wireless Communications, vol. 17, no. 1, pp. 104-111, 2010.

[16] Z. J. Haas, M. R. Pearlman, e P. Samar, The Zone Routing Protocol (ZRP) for Ad Hoc Networks. IETF Internet Draft, 2002.

[17] M. Dorigo e T. Stützle, Ant Colony Optimization. Cambridge, MA MIT University Press Group Ltd, 2004.

[18] F. Heylighen, "Stigmergy as a universal coordination mechanism I: Definition and components," Cognitive Systems Research, vol. 38, 2016.

[19] F. Correia e T. Vazão, "Simple Ant Routing Algorithm," Ad Hoc Networks, vol. 8, no. 8, pp. 810-823, Nov. 2010.

[20] Z. Albayrak e A. Zengin, "Bee-MANET: A New Swarm-based Routing Protocol for Wireless Ad Hoc Networks," Electronics and Electrical Engineering, vol. 20, no. 3, mar 2014.

[21] T. Cavalier-Smith, "Protist phylogeny and the high-level classification of Protozoa," European Journal of Protistology, vol. 39, no. 4, jan 2003.

[22] Pixabay, "Stunning Free Images," 2018. [Online]. Available: https: / / pixabay.com/

[23] S. Olsson, "Colonial Growth of Fungi," in Biology of the Fungal Cell. Berlim: Springer, 2001.

[24] R. E. Falconer, J. L. Bown, N. A. White, e J. W. Crawford, "Biomass recycling and the origin of phenotype in fungal mycelia," Proceedings of the Royal Society B: Biological Sciences, vol. 272, aug 2005.

[25] X. Hao, R. Falconer, D. Bradley, e J. Crawford, "FUNNet - A Novel Biologically-Inspired Routing Algorithm Based on Fungi," in 2009 Second International Conference on Communication Theory, Reliability, and Quality of Service, jul 2009.

[26] G. D. Caro, F. Ducatelle, e L. M. Gambardella, "AntHocNet: An AntBased Hybrid Routing Algorithm for Mobile Ad Hoc Networks," in Lecture Notes in Computer Science. Berlim: Springer, 2004.

[27] S. Kurkowski, T. Camp, e M. Colagrosso, "Manet simulation studies: The incredibles," SIGMOBILE Mob. Comput. Commun. Rev., vol. 9, no. 4, p. 50-61, Oct. 2005.

[28] T. Camp, J. Boleng, e V. Davies, "A survey of mobility models for ad hoc network research," Wireless Communications and Mobile Computing, vol. 2, no. 5, pp. 483-502, 2002. 